\title{
Synthesis and characterization of cellulose/ hydroxyapatite based dental restorative composites
}

Muhammad Sabir, Asif Ali, Usama Siddiqui, Nawshad Muhammad, Abdul Samad Khan, Faiza Sharif, Farasat Iqbal, Asma Tufail Shah, Abdur Rahim \& Ihtesham Ur Rehman

To cite this article: Muhammad Sabir, Asif Ali, Usama Siddiqui, Nawshad Muhammad, Abdul Samad Khan, Faiza Sharif, Farasat Iqbal, Asma Tufail Shah, Abdur Rahim \& Ihtesham Ur Rehman (2020): Synthesis and characterization of cellulose/hydroxyapatite based dental restorative composites, Journal of Biomaterials Science, Polymer Edition, DOI: 10.1080/09205063.2020.1777827

To link to this article: https://doi.org/10.1080/09205063.2020.1777827

Accepted author version posted online: 04 Jun 2020.

Submit your article to this journal ๘

Q View related articles $\sqsubset$

View Crossmark data $\nearrow$ 


\title{
Synthesis and characterization of cellulose/ hydroxyapatite based dental restorative composites
}

\author{
Muhammad Sabir ${ }^{1}$, Asif Ali $^{1}$, Usama Siddiqui ${ }^{2}$, Nawshad Muhammad ${ }^{1}$, Abdul Samad Khan ${ }^{3}$, \\ Faiza Sharif ${ }^{1}$, Farasat Iqbal ${ }^{1}$, Asma Tufail Shah ${ }^{1}$, Abdur Rahim ${ }^{1}$, Ihtesham Ur Rehman ${ }^{4}$ \\ ${ }^{1}$ Interdisciplinary Research Centre in Biomedical Materials (IRCBM), COMSATS University \\ Islamabad, Lahore Campus, Lahore, Pakistan. \\ ${ }^{2}$ Department of Dental Materials, Rehman College of Dentistry, Peshawar, Pakistan \\ ${ }^{3}$ Department of Restorative Dental Sciences, College of Dentistry, Imam Abdulrahman Bin \\ Faisal University, Dammam 31441, Saudi Arabia \\ ${ }^{4}$ Engineering Department, Lancaster University, Lancaster, UK
}

*Corresponding authors email ID: nawshadmuhammad@cuilahore.edu.pk, akhan@iau.edu.sa

\begin{abstract}
The aim of this study was an in-situ synthesis of hydroxyapatite (HA) on cellulose fibers to be used as a new reinforcing agent for dental restorations. The microwave irradiation method was used for synthesis and the materials were characterized with analytical techniques. The prepared dental resin composites were mechanically tested by a universal testing machine and electrodynamic fatigue testing system. FTIR, XRD, SEM/EDS analysis confirmed the successful synthesis of HA on cellulose fibers. The Alamar blue biocompatibility assay showed more than $90 \%$ cell viability for the prepared cellulose/HA. The mechanical properties of resin composites improved with cellulose content from $30 \mathrm{wt} . \%$ to $50 \mathrm{wt} . \%$ in the polymer matrix. Substantially, increasing the cellulose/HA content from $40 \%$ to $50 \%$ improved the mechanical properties. The results suggested that HA could be successfully synthesized on cellulose fibers using microwave irradiation and contributed to improving the mechanical properties of dental resin composites.
\end{abstract}


Keywords: Hydroxyapatite; Cellulose; Biocompatibility; Dental composites; Mechanical properties

\section{Introduction:}

With the increasing dental awareness, the prevalence of dental caries has decreased hence ensuing the shift from restorative dentistry to modern dentistry (1). Conventionally, dental composites are composed of fillers (inorganic materials i.e., modified silica particles), resin matrix i.e. monomer system (mainly bisphenol A glycidyldimethylmethacrylate (bis-GMA), urethane dimethacrylate (UDMA), and tetraethylene glycol dimethacrylate (TEGDMA)), and silane coupling agents (2). Dental composites have proved to be one of the major successes in the domain of dental restorative materials (3). However, many shortcomings such as polymerization shrinkage, microleakage, post-operative sensitivity, and toxicity are associated with them (4-6). Recently, bioceramics such as amorphous calcium phosphate, mono-calcium phosphate, bioactive glass, and hydroxyapatite have been added as reinforcing agents in dental restorative materials $(7,8)$. The inclusion of these bioceramics in dental composites have gained interest due to their potential to mimic the desired tooth structure, however, they have inferior mechanical properties $(9,10)$.

Cellulose is considered a promising reinforcing material and finds many applications in the field of filtration membrane, biotechnology, and regenerative medicine because of its high mechanical properties. The addition of cellulose in dental restorative materials has shown a positive influence on mechanical properties (11). It is reported that nano-hydroxyapatite (nHA) has been dispersed on cellulose nanofibers and showed promising results for bone regeneration (12). 
The use of dental composites especially in the posterior region requires significant mechanical properties because of higher mechanical load due to cyclic chewing forces on these restorations (13-16). These factors reduce the effectiveness of restoration over time hence the need for improvement. These shortcomings lead to the development of new and better material that has significant and improved mechanical properties $(17,18)$.

Therefore, in this study, an attempt has been taken to synthesize by the in situ growth of hydroxyapatite (HA) crystals on the surface of cellulose micro-crystalline using microwave irradiation technique. The microwave irradiation technique has been used to synthesize nanoapatites and appeared as a cost-effective technique $(19,20)$. The prepared HA/cellulose was incorporated in the dental resin matrix as a reinforcing agent. The null hypothesis was that the inclusion of this reinforcing would improve the mechanical properties of dental composite.

\section{Materials and Methods:}

Synthesis of cellulose/hydroxyapatite

All chemicals used in this study were of analytical grade and the chemicals used to synthesize cellulose/hydroxyapatite were purchased from Merck, Germany. Hydroxyapatite (HA) was fabricated by using a microwave irradiation technique as described by our group previously (21). Calcium nitrate tetrahydrate $\left(\mathrm{Ca}\left(\mathrm{NO}_{3}\right)_{2} \cdot 4 \mathrm{H}_{2} \mathrm{O}\right.$ : $\left.99 \%\right)$ and Diammonium hydrogen phosphate $\left(\left(\mathrm{NH}_{4}\right)_{2} \mathrm{HPO}_{4}\right)$ were used as calcium and phosphate precursors, respectively. Distilled water was used as a solvent for precursors. $0.5 \mathrm{M}\left(\mathrm{Ca}\left(\mathrm{NO}_{3}\right)_{2} .4 \mathrm{H}_{2} \mathrm{O}\right.$ and $0.29 \mathrm{M}\left(\left(\mathrm{NH}_{4}\right)_{2} \mathrm{HPO}_{4}\right)$ solutions were prepared to keep 1.67 initial $\mathrm{Ca} / \mathrm{P}$ molar ratios. Both the solutions were stirred for $30 \mathrm{~min}$ at room temperature. Cellulose fibers $(30 \%, 40 \%$, and $50 \% \mathrm{wt} / \mathrm{wt})$ were added in $\left(\mathrm{Ca}\left(\mathrm{NO}_{3}\right)_{2} .4 \mathrm{H}_{2} \mathrm{O}\right.$ solution..Ammonium hydroxide was added to maintain the $\mathrm{pH}$ around 11 while adding $\left(\left(\mathrm{NH}_{4}\right)_{2} \mathrm{HPO}_{4}\right)$ dropwise into $\left(\mathrm{Ca}\left(\mathrm{NO}_{3}\right)_{2} \cdot 4 \mathrm{H}_{2} \mathrm{O}\right)$ solution. The solution was refluxed in the 
microwave oven (Samsung MW101P, Hwaseong, South Korea) for 3 min at 1000W with 15s ON:OFF intervals. After that, the solutions were filtered and washed with distilled water until the $\mathrm{pH}$ became 7 and then dried in an oven at $100^{\circ} \mathrm{C}$ overnight. The powders obtained from each reaction were then grounded in mortar and pestle and 30\%, 40\%, and 50\% wt/wt cellulose/HA denoted as A, B, and C, respectively Synthesis of cellulose/hydroxyapatite based dental composites All the compositional materials were purchased for Sigma Aldrich and were of analytical grade. Initially, the ratio of monomers i.e. bis-GMA, UDMA, and TEGDMA was set at 40:35:25, respectively and weight percentages were set as per these ratios. The required amount of these monomers were mixed for $30 \mathrm{~min}$ at room temperature. Then $0.5 \mathrm{wt}, \%$ photoinitiator $(\mathrm{CQ})$ and $0.5 \mathrm{wt} . \%$ co-initiator (EDMAB) was added and the reaction was conducted in a dark environment to avoid premature polymerization. The mixing was conducted for a further $30 \mathrm{~min}$. After optimizing the concentration of reinforcing agents (cellulose/HA), the final weight percentages of $\mathrm{A}, \mathrm{B}$, and $\mathrm{C}$ samples in the resin matrix was $40 \%$ and $50 \%$. In total six different compositional variants were made with two different percentages from each percentage of cellulose in cellulose/HA. The details of each variant are given in Table 1. 
Characterization of cellulose/ hydroxyapatite

Fourier transform infrared spectrophotometer (FTIR, Nicolet 6700, USA) was used for functional group analysis over the region of $500-4000 \mathrm{~cm}^{-1}$ with the resolution of $8 \mathrm{~cm}^{-1}$ averaging to about 128 scans. Powder X-ray_diffraction (XRD) patterns were obtained using PANalytical X'Pert Powder X-ray diffractometer with monochromatic $\mathrm{Cu}-\mathrm{K}_{\mathrm{a}}$ radiations $\left(\lambda=1.54 \AA\right.$ ) . Scans were obtained in the $2 \theta$ range $\approx 20-80^{\circ}$, with a step size of $0.02^{\circ}$ every 1 s. Scanning electron microscope (Vega LMU TESCAN Brno, Czech Republic) was used for surface analysis of the samples and elemental analysis was performed with the help of energy dispersive spectroscopy (EDS) using Inca X-Act EDS detector (Oxford Instruments, UK). Evaluation of Biological compatibility

Each concentration of cellulose/HA powders was evaluated for its biological compatibility through the fibroblast cell line (NIH/3T3 ATCC ${ }^{\circ}$ CRL-1658 lines were cultured and expanded as described previously (22) and samples from each group were sterilized by using a method mentioned in the literature (23). The hematocytometer and microscope were used to count 50,000 cells for seeding on each sample in the 24 well plates to evaluate the compatibility of the NIH3T3 cells with cellulose/HA powders. The samples from each group $(1 \mathrm{mg})$ were mixed with $1 \mathrm{mLof}$ DMEM media. Cells were cultured on tissue culture plastic plates without samples to use as a control.

Alamar Blue Assay Test

Alamar blue assay was performed for the test and control samples after three days of culturing. To the seeded samples of test and control, $0.5 \mathrm{~mL}$ of $1 \mathrm{mM}$ Alamar Blue solution (Sigma Aldrich, UK) was added and incubated for $3-4 \mathrm{~h}$ at $37^{\circ} \mathrm{C}$. Fluorescence plate reader (PR4100 Absorbance 
Microplate Reader BIO-RAD, UK) was used to measure the absorbance at $570 \mathrm{~nm}$. The analysis was done in triplicate.

Mechanical properties of experimental dental composites:

The mechanical properties i.e. Vickers hardness, compressive strength, flexural strength/modulus, and biaxial flexural strength of the prepared dental composite were measured as per ASTM D695-15, ASTM D790-15, ISO 6872:2008 for compression strength, flexural strength/modulus, and biaxial flexural strength, respectively. The detail methodologies have been provided in supporting information.

\section{Result and Discussion:}

The cellulose/HA powders were successfully synthesized using microwave irradiation technique. The microwave irradiation technique is a quicker way to achieve nano- and micro-particles on a large scale (20). Compared to conventional synthesis methods, microwave irradiation technology emerged with advantages such as shorter reaction time (usually in minutes), high efficiency, energy savings, and provide efficient and uniform reactions (24).

FTIR spectroscopy was performed to confirm the in-situ deposition of HA grown on microcrystalline cellulose. Cellulose (a), HA (b), and cellulose/HA powders c, d, and e (Figure 1) have a broad band at $3570-3312 \mathrm{~cm}^{-1}$, assigned to the $\mathrm{O}-\mathrm{H}$ group (25). The asymmetric and symmetric stretching peaks of C-H appeared at $2970 \mathrm{~cm}^{-1}$ and $2910 \mathrm{~cm}^{-1}$, respectively. While in the HA spectrum, the $\mathrm{OH}$ stretching peak was observed from $3600-3050 \mathrm{~cm}^{1}$. The peak at 1433 $\mathrm{cm}^{-1}$ assigned to the asymmetric stretching and out of plane bending mode of carbonate group $\left(\mathrm{CO}_{3}{ }^{-2}\right)$ from $\mathrm{HA}$ (26). The phosphate group $\left(\mathrm{PO}_{4}{ }^{-3}\right)$ of $\mathrm{HA}$ was identified by asymmetric bending vibrations at $1039 \mathrm{~cm}^{-1}$. The peaks assigned to cellulosic anhydroglucopyranose 
vibration results from deformation, wagging, and twisting modes were observed from 600 to $1800 \mathrm{~cm}^{-1}$. Thus, the spectral analysis confirms the in-situ growth of HA on cellulose.

The XRD pattern of the cellulose/HA showed (Figure 2) broad peaks at $2 \theta$ values of 22.4 (crystal plane 200) and 32.2 (crystal plane 211), assigned to cellulose (JCPDS pattern number 00-502241) and HA (JCPDS: 9-432), respectively $(25,26)$. It was observed that with the increase in the concentration of cellulose in HA the peak intensity $(2 \theta \sim 22.4)$ was increased. In contrast, the peak intensity assigned to HA $(2 \theta \sim 32.2)$ was noted to decrease.

The SEM analysis of microcrystalline cellulose and cellulose/HA (30\%, 40\%, and 50\%) showed (Figure 3) the irregular shapes and various sizes of the particles in the range of micron. Moreover, the surface of microcrystalline cellulose was clear and smooth while for that cellulose/HA samples, the surfaces were rough because of the deposition and growth of HA on the cellulose particles. The presence of HA was confirmed with the presence of $\mathrm{Ca}$ and $\mathrm{P}$ by EDX analysis as tabulated in Table 2. While for cellulose, the $\mathrm{Ca}$ and $\mathrm{P}$ were not present, which confirmed the in-situ growth of HA on cellulose.

Cell viability

The Alamar blue assay was performed on control and cellulose/HA samples to investigate their biocompatibility with NIH3T3 (fibroblast cell line) as shown in Figure 4. The results showed that all three compositions of cellulose/HA have shown cell viability within an acceptable range. The cell viability (\%) of control, experimental samples A, B, and C was $100 \pm 5.0 \%, 90.7 \pm 4.5$ $\%, 93.2 \pm 4.7 \%$, and $96.2( \pm 4.8)$, respectively. Whereby, with the increase in the concentration of cellulose, cell viability was increased. This decrease in cell viability with a higher concentration of HA might be related to the ionic structure of hydroxyapatite (electrostatic interactions among $\mathrm{OH}$ and $\mathrm{PO}_{4}^{-}$groups of $\mathrm{HA}$ with cell membrane causes the rapture of cells (27). In general, the 
hydrophilic materials showed viability. These results are in accordance with previous studies, where cell viability was decreased with the increased concentration of HA (28). Mechanical properties of resin composite.

Tensile, compression, and shear are three simplest types of stresses, which form the basis of all other complex patterns of stresses i.e. flexural. Dental filling materials subjected to all these types of simple stresses to evaluate the mechanical performance of these materials should be considered. Resin composite with strong mechanical properties is crucial for their long-term use in the clinic application of dental restoratives. To evaluate the mechanical performance and assess the reinforcing effect of cellulose-HA, Vickers micro-hardness, compression strength, flexural strength, flexural modulus, and biaxial flexural strength of dental resin composites loaded with $40 \mathrm{wt} \%, 50 \mathrm{wt} \%$ of cellulose/HA (30wt. $\%, 40 \mathrm{wt} . \%$ and $50 \mathrm{wt} . \%)$ were measured, and results are tabulated in supporting information. The recipe of resin monomers is the gold standard using in the fabrication of dental composite. The reaction kinetic process occurs during the polymerization process and conversion of $\mathrm{C}=\mathrm{C}$ to $\mathrm{C}-\mathrm{C}$ (29). With the increase in the concentration of cellulose/HA particles, the volume of resin monomers reduces, and it could be one of the reasons to get variation in mechanical properties with a change in cellulose/HA particles concentration. It is reported that if high concentration (i.e. $60 \%$ or more) of HA particles was used as a reinforcing agent in dental resin composite, then there were issues related to photo-polymerization due to high refractive index of HA (1.67) (21).

The hardness results revealed that there was an increase in micro-hardness with the incorporation of cellulose/HA particles as shown in Figure 5. It is evidenced that the increase in microhardness between group A1 and group B1, having $30 \mathrm{wt} . \%$ and $40 \mathrm{wt} . \%$ cellulose respectively was not significant as compared to group C1 having $50 \mathrm{wt} . \%$ cellulose. The micro-hardness of 
groups A, B, and C for $40 \%$ filler content was increased from 25.9 to 30.1 and for $50 \%$ filler content hardness increased from 28.23 to 36.59 . Overall, a $16.22 \%$ increase was observed in resin composites loaded with $40 \%$ filler particles and a $29.62 \%$ increase was observed in resin composites loaded with 50\% filler particles. The increasing percentage incorporation of the hard phase of cellulose/HA particles into the ductile resin phase was responsible for higher surface hardness. This could be due to the high stiffness of cellulose/HA particles than the resin matrix (30). The surface hardness significantly increased as cellulose mass fraction increases. This increase in surface hardness was due to that a chemical bonding might be formed between cellulose and polymer resin matrix as polymer contained carbonyl group, which might be bonded with the hydroxyl group of cellulose and more energy was required to break the bond. The results of micro-hardness are in accordance with previous studies, whereby $50 \mathrm{wt} \%$ and $60 \mathrm{wt}$. $\%$ hydroxyapatite was added in the dental resins and showed hardness of $38 \mathrm{VHN}$ and $35 \mathrm{VHN}$, respectively (31).

The resin composite A1, loaded with $40 \%$ cellulose/HA particles that contained $30 \%$ cellulose had a compressive strength of $57.06 \pm 7.89 \mathrm{MPa}$ lowest among all, whereas the composite $\mathrm{C} 2$, loaded with 50\% cellulose/HA particles that contained 50\% cellulose showed the highest average compressive strength among all $(98.21 \pm 1.19 \mathrm{MPa})$, shown in Figure 6. It is evident that increase incorporation of cellulose mass fraction from $30 \%$ to $50 \%$ significantly increased the compressive strength. Similarly, the increase in the loading of filler particles from $40 \%$ to $50 \%$ significantly increased the compressive strength. Moreover, an increase in compressive strength among all samples was not significant as cellulose mass fraction increased. However, an increase in the loading of cellulose/HA particles significantly increases the compressive strength. These results indicated that increase loading of filler particles along with the incorporation of a higher 
mass fraction of cellulose improved the compressive properties of resin composites. The reason could be that cellulose/HA was strongly embedded into the matrix, which strengthened the resin and resulted in an increase of the strength, moreover, the density of the composite was improved, enhanced the values of compressive strength. Furthermore, the trend of strength improvements implied that the reinforcing effect of cellulose could be weakened when cellulose loading was higher, which might be possibly due to the undesirable distribution of cellulose. These findings are in comparison to the previous study, in which only nHA and then different percentages of carbon nanotubes and nHA were added in dental resins and different groups showed compressive strength ranging between $63 \mathrm{MPa}$ (only nHA) to $100 \mathrm{MPa}(3 \%$ carbon/nHA) (21).

The resin composite B1 showed the flexural strength of $32.8 \pm 6.39 \mathrm{MPa}$, lowest among all, whereas composite $\mathrm{C} 2$ showed the highest flexural strength among all (50.0 $\pm 6.99 \mathrm{MPa})$, shown in Figure 7. It is noticed that an increase in the mass fraction of cellulose increased the flexural strength value. However, this increase was not significant ( $\mathrm{p} \geq 0.05)$ except for sample $\mathrm{C} 2$ in which the increase was significant $(p \leq 0.05)$. It can also be observed that an increase in the loading of cellulose/HA filler particles significantly increased the flexural strength. The current data matches with the flexural strength of HA-based dental composites (31).

The composite A2, loaded with $50 \%$ filler particles that contained $30 \%$ cellulose had flexural modulus value of $6.11 \pm 0.72 \mathrm{GPa}$ lowest among all, whereas composite $\mathrm{C}$, loaded with $40 \%$ cellulose/HA particles that had 50\% cellulose as a component showed highest flexural modulus value $(9.85 \pm 6.01 \mathrm{GPa})$ among all as shown in Figure 7. In contrast to flexural strength results, it was observed that an increase in the mass fraction of cellulose increased the flexural modulus, whereas an increase in cellulose/HA particle concentration decreased the flexural modulus. The 
results of flexural modulus are following previously done studies, in which experimental groups showed flexural modulus ranging between $4 \mathrm{GPa}$ to $9.5(31,32)$.

Resistance to fracture of an object is depicted by its flexural strength while modulus defines the rigidity or relative stiffness of the object (33). It is clear from the results that increasing cellulose mass fraction increased both the flexural strength and modulus, albite in $40 \%$ filler no as such a trend was observed for flexural strength. The modulus of cellulose was higher than that of the resin matrix, which improved the rigidity of experimental composites leading to the substantial increase of flexural modulus. However, different elastic moduli or nature of the resin matrix and filler materials resulted in different behavior of dental restoratives, held responsible for the insignificant increase in strength ( $\mathrm{p} \geq 0.05)$ except for composite $\mathrm{C} 2(\mathrm{p} \leq 0.05)$. The composite has a chemical bonding at the resin matrix and filler particle interface. If the interface has good bonding, the mechanical properties will eventually improve due to the even distribution of stresses. Hence, it is presumed that chemical bonding between cellulose and resin matrix improved as cellulose mass fraction increases resulting ductile behavior of experimental composites, which is responsible for increased flexural strength and modulus. This could be due to the improved packing density of composite and decreased bonding between organic and inorganic matrices, which can be mitigated by adding a crosslinking agent or coupling agent (34).

The composite B1, loaded with $40 \%$ cellulose/HA particles containing $40 \%$ cellulose had a biaxial flexural strength value of $(81.53 \pm 8.98 \mathrm{MPa})$ lowest among all. Whereas composite $\mathrm{C} 2$, loaded with 50\% cellulose/HA particles containing 50\% cellulose had the highest biaxial flexural strength $(115.65 \pm 11.42 \mathrm{MPa})$ among all. It is noticed that with increased incorporation of cellulose content, both in $40 \%$ and $50 \%$ loaded filler composites, biaxial flexural strength 
increased except in the case of composite B1, where strength was slightly decreased that could be due to uneven distribution of filler particles or formation of agglomerates. However, this change in strength value was not significant $(p \geq 0.05)$. Chemical adhesion and strong interlocking of filler particles resulted in improved biaxial flexural strength. The chemical bonding between organic and inorganic matrices improved due to the presence of the carbonyl group in the resin matrix and hydroxyl group in filler particle as discussed earlier. It is evidenced from the SEM micrograph (Figure 3) that HA was grown on cellulose surface making it rougher hence providing sites for mechanical interlocking in the polymer matrix, which led to higher biaxial flexural strength. It was found with the increase in filler content in experimental resin composites biaxial flexural strength value substantially increased. This might be because of the low residual stresses generated in the experimental composites. The residual stresses, generated by the resin shrinkage during curing, considered a critical challenge for resin composites for dental restorative applications. As bis-GMA and TEGDMA shrink $6.1 \%$ and $14.3 \%$, respectively during curing in response to polymerization, therefore, higher loading of inorganic filler particles was used in commercial dental composite to reduce the percentage shrinkage to about $2 \%$ (35, 36). These current findings are better than the results reported by Chen. et, al in which $40 \mathrm{wt} \%$ hydroxyapatite was used as a dental filler and it showed maximum mean biaxial flexural strength of 42MPa (35). These results are in good agreement with literature that increases in filler content improve the mechanical properties of resin composites (37).

\section{Conclusion}

Hydroxyapatite crystals have been grown on microcrystalline cellulose to fabricate biocompatible reinforcing agents for dental restorative material. The microwave irradiation technique was used to grow HA with various concentrations of cellulose. The FTIR and XRD 
analysis showed the characteristic peaks assigned to cellulose and HA. SEM analysis showed the deposition and growth of hydroxyapatite on the cellulose particles. The cellulose/HA particles were assessed biocompatible in the cell viability assay. Overall, the experimental dental composites with high loading (50 wt.\%) of cellulose/HA particles showed increased mechanical values i.e., micro-hardness, compressive strength, flexural strength/modulus, and bi-axial flexural strength. These results showed that cellulose/HA particles can potentially be used as a reinforcing agent in dental restorative materials.

\section{Acknowledgment}

This work has been supported by Interdisciplinary Research Centre in Biomedical

Materials (IRCBM) COMSATS University Islamabad, Lahore Campus, Pakistan, and Higher

Education Commission of Pakistan under the scheme of National Research Program for Universities, Project No. 4146.

\section{References}

1. Sofola O, Folayan M, Oginni A. Changes in the prevalence of dental caries in primary school children in Lagos State, Nigeria. Nigerian journal of clinical practice. 2014;17(2):127-33.

2. Leprince JG, Palin WM, Hadis MA, Devaux J, Leloup G. Progress in dimethacrylate-based dental composite technology and curing efficiency. Dental Materials. 2013;29(2):139-56.

3. Randolph LD, Palin WM, Leloup G, Leprince JG. Filler characteristics of modern dental resin composites and their influence on physico-mechanical properties. Dental Materials. 2016;32(12):158699.

4. Porto I. Post-operative sensitivity in direct resin composite restorations: clinical practice guidelines. IJRD. 2012;1:1-12.

5. Milosevic M. Polymerization mechanics of dental composites-advantages and disadvantages. Procedia Engineering. 2016;149:313-20.

6. Susila AV, Balasubramanian V. Correlation of elution and sensitivity of cell lines to dental composites. Dental Materials. 2016;32(3):e63-e72.

7. Khalid H, Syed MR, Rahbar MI, Iqbal H, Ahmad S, Kaleem M, et al. Effect of nano-bioceramics on monomer leaching and degree of conversion of resin-based composites. Dent Mater J. 2018;37(6):940-

9. 
8. Khan AS, Syed MR. A review of bioceramics-based dental restorative materials. Dent Mater J. 2019;38(2):163-76.

9. Lizzi F, Villat C, Attik N, Jackson P, Grosgogeat B, Goutaudier C. Mechanical characteristic and biological behaviour of implanted and restorative bioglasses used in medicine and dentistry: $A$ systematic review. Dental Materials. 2017;33(6):702-12.

10. Yin L, Song X-F, Song Y-L, Huang T, Li J. An overview of in vitro abrasive finishing \& CAD/CAM of bioceramics in restorative dentistry. International Journal of Machine Tools and Manufacture. 2006;46(9):1013-26.

11. Wang $\mathrm{Y}$, Hua H, Li W, Wang R, Jiang X, Zhu M. Strong antibacterial dental resin composites containing cellulose nanocrystal/zinc oxide nanohybrids. Journal of dentistry. 2019;80:23-9.

12. Yamaguchi K, Prabakaran M, Ke M, Gang X, Chung IM, Um IC, et al. Highly dispersed nanoscale hydroxyapatite on cellulose nanofibers for bone regeneration. Materials Letters. 2016;168:56-61.

13. Anseth K, Newman S, Bowman C. Polymeric dental composites: properties and reaction behavior of multimethacrylate dental restorations. Biopolymers li: Springer; 1995. p. 177-217.

14. Lovell LG, Lu H, Elliott JE, Stansbury JW, Bowman CN. The effect of cure rate on the mechanical properties of dental resins. Dental Materials. 2001;17(6):504-11.

15. Ferracane JL. Placing dental composites - a stressful experience. Operative Dentistry. 2008;33(3):247-57.

16. Braga RR, Ballester RY, Ferracane JL. Factors involved in the development of polymerization shrinkage stress in resin-composites: a systematic review. Dental materials. 2005;21(10):962-70.

17. Cramer N, Stansbury J, Bowman C. Recent advances and developments in composite dental restorative materials. Journal of dental research. 2011;90(4):402-16.

18. Minguez N, Ellacuria J, Soler JI, Triana R, Ibaseta G. Advances in the history of composite resins. Journal of the History of Dentistry. 2003;51(3):103-5.

19. Nazir R, Khan AS, Ahmed A, Ur-Rehman A, Chaudhry AA, Rehman IU, et al. Synthesis and in-vitro cytotoxicity analysis of microwave irradiated nano-apatites. Ceramics International. 2013;39(4):4339-47.

20. Khalid H, Suhaib F, Zahid S, Ahmed S, Jamal A, Kaleem M, et al. Microwave-assisted synthesis and in vitro osteogenic analysis of novel bioactive glass fibers for biomedical and dental applications. Biomedical Materials. 2018;14(1):015005.

21. Khan A, Hussain A, Sidra L, Sarfraz Z, Khalid H, Khan M, et al. Fabrication and in vivo evaluation of hydroxyapatite/carbon nanotube electrospun fibers for biomedical/dental application. Materials Science and Engineering: C. 2017;80:387-96.

22. Colpankan Gunes O, Unalan I, Cecen B, Ziylan Albayrak A, Havitcioglu H, Ustun O, et al. Threedimensional silk impregnated HAp/PHBV nanofibrous scaffolds for bone regeneration. International Journal of Polymeric Materials and Polymeric Biomaterials. 2019;68(5):217-28.

23. Kouhi M, Fathi M, Prabhakaran MP, Shamanian M, Ramakrishna S. Poly L lysine-modified PHBV based nanofibrous scaffolds for bone cell mineralization and osteogenic differentiation. Applied Surface Science. 2018;457:616-25.

24. Cai Z-Y, Peng F, Zi Y-P, Chen F, Qian Q-R. Microwave-Assisted Hydrothermal Rapid Synthesis of Calcium Phosphates: Structural Control and Application in Protein Adsorption. Nanomaterials (Basel). 2015;5(3):1284-96.

25. Man Z, Muhammad N, Sarwono A, Bustam MA, Kumar MV, Rafiq S. Preparation of cellulose nanocrystals using an ionic liquid. Journal of Polymers and the Environment. 2011;19(3):726-31.

26. Muhammad N, Gao Y, Iqbal F, Ahmad P, Ge R, Nishan U, et al. Extraction of biocompatible hydroxyapatite from fish scales using novel approach of ionic liquid pretreatment. Separation and Purification Technology. 2016;161:129-35. 
27. Santos C, Gomes P, Duarte J, Franke R, Almeida M, Costa M, et al. Relevance of the sterilizationinduced effects on the properties of different hydroxyapatite nanoparticles and assessment of the osteoblastic cell response. Journal of The Royal Society Interface. 2012;9(77):3397-410.

28. Iqbal B, Sarfaraz Z, Muhammad N, Ahmad P, Iqbal J, Khan ZUH, et al. Ionic liquid as a potential solvent for preparation of collagen-alginate-hydroxyapatite beads as bone filler. Journal of Biomaterials science, Polymer edition. 2018;29(10):1168-84.

29. Watts DC. Reaction kinetics and mechanics in photo-polymerised networks. Dental Materials. 2005;21(1):27-35.

30. Lung CYK, Sarfraz Z, Habib A, Khan AS, Matinlinna JP. Effect of silanization of hydroxyapatite fillers on physical and mechanical properties of a bis-GMA based resin composite. Journal of the mechanical behavior of biomedical materials. 2016;54:283-94.

31. Arcís RW, López-Macipe A, Toledano M, Osorio E, Rodríguez-Clemente R, Murtra J, et al. Mechanical properties of visible light-cured resins reinforced with hydroxyapatite for dental restoration. Dental Materials. 2002;18(1):49-57.

32. Labella R, Braden M, Deb S. Novel hydroxyapatite-based dental composites. Biomaterials. 1994;15(15):1197-200.

33. Plotino G, Grande NM, Bedini R, Pameijer CH, Somma F. Flexural properties of endodontic posts and human root dentin. Dental Materials. 2007;23(9):1129-35.

34. Zhang X, Chen P, Kang X, Chen M, Wang Q. Improvement of the interfacial adhesion between PBO fibers and PPESK matrices using plasma-induced coating. Journal of Applied Polymer Science. 2012;123(5):2945-51.

35. Chen L, Yu Q, Wang Y, Li H. BisGMA/TEGDMA dental composite containing high aspect-ratio hydroxyapatite nanofibers. Dental Materials. 2011;27(11):1187-95.

36. Wille S, Hölken I, Haidarschin G, Adelung R, Kern M. Biaxial flexural strength of new BisGMA/TEGDMA based composites with different fillers for dental applications. Dental Materials. 2016;32(9):1073-8.

37. Ikejima I, Nomoto R, McCabe JF. Shear punch strength and flexural strength of model composites with varying filler volume fraction, particle size and silanation. Dental Materials. 2003;19(3):206-11. 
Table 1: Composition of dental composites

\begin{tabular}{|l|l|l|l|l|}
\hline Group ID & Filler Composition & \multirow{2}{*}{ Sample ID } & \multicolumn{2}{|l|}{ Composite Composition } \\
\cline { 4 - 5 } & (Cellulose/HA) & & Filler & Monomer \\
\hline A & $30 \%$ Cellulose of HA & A1 & $40 \%$ & $60 \%$ \\
\cline { 3 - 5 } & & A2 & $50 \%$ & $50 \%$ \\
\hline \multirow{2}{*}{ B } & $40 \%$ Cellulose of HA & B1 & $40 \%$ & $60 \%$ \\
\cline { 3 - 5 } & & B2 & $50 \%$ & $50 \%$ \\
\hline C & $50 \%$ Cellulose of HA & C1 & $40 \%$ & $60 \%$ \\
\cline { 3 - 5 } & & C2 & $50 \%$ & $50 \%$ \\
\hline
\end{tabular}

Table 2: EDX analysis of cellulose /hydroxyapatite

\begin{tabular}{|l|l|l|l|l|}
\hline & cellulose & $\begin{array}{l}30 \% \text { Cellulose } \\
\text { of HA }\end{array}$ & $\begin{array}{l}40 \% \text { Cellulose of } \\
\text { HA }\end{array}$ & $\begin{array}{l}50 \% \text { Cellulose of } \\
\text { HA }\end{array}$ \\
\hline $\mathbf{C}$ & 49.04 & 40.64 & 41.38 & 49.69 \\
\hline $\mathbf{O}$ & 50.96 & 40.85 & 38.25 & 35.80 \\
\hline $\mathbf{C a}$ & & 5.81 & 6.49 & 4.37 \\
\hline $\mathbf{P}$ & & 12.69 & 13.89 & 10.14 \\
\hline & $\mathbf{1 0 0}$ & $\mathbf{1 0 0}$ & $\mathbf{1 0 0}$ & $\mathbf{1 0 0}$ \\
\hline
\end{tabular}




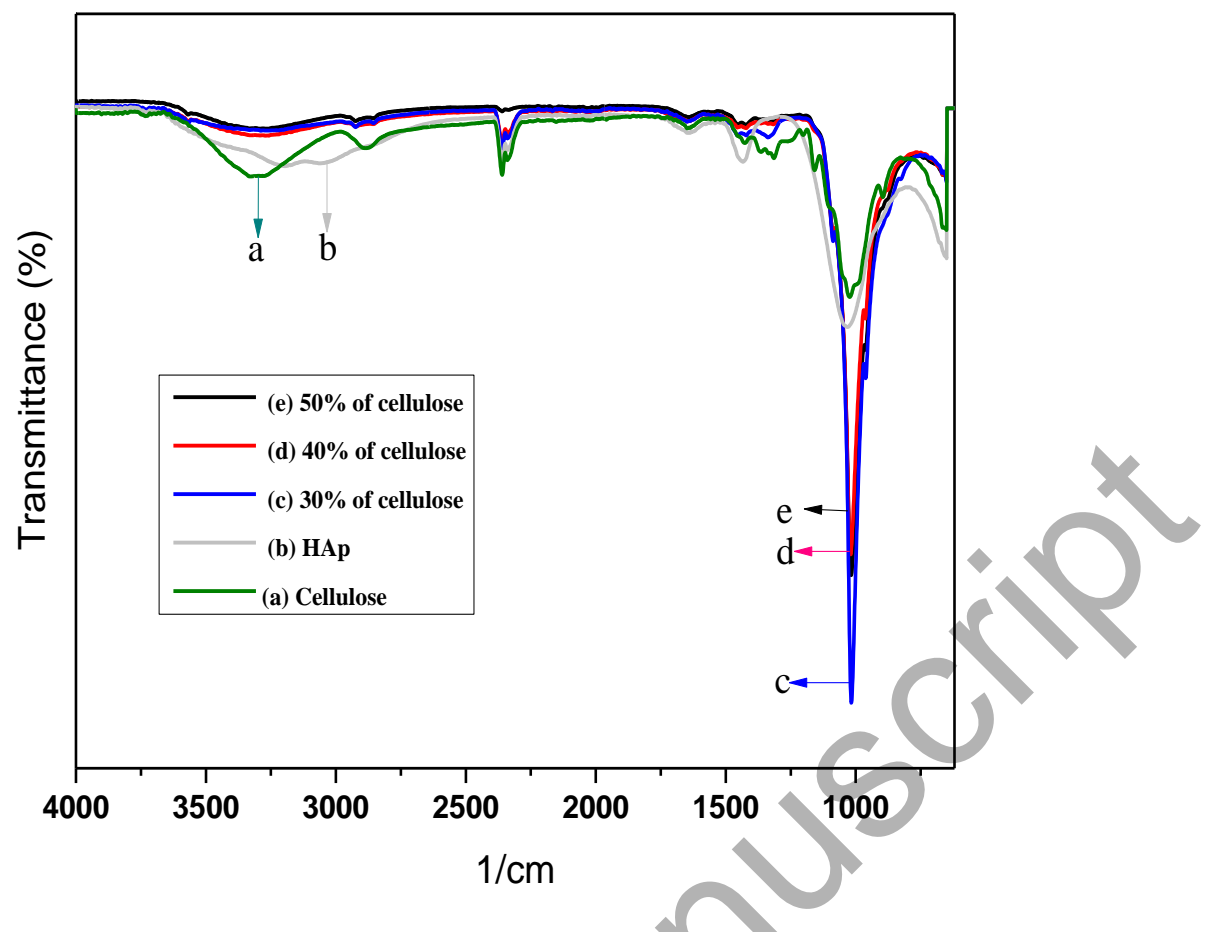

Figure 1: FTIR analysis of cellulose/hydroxyapatite 


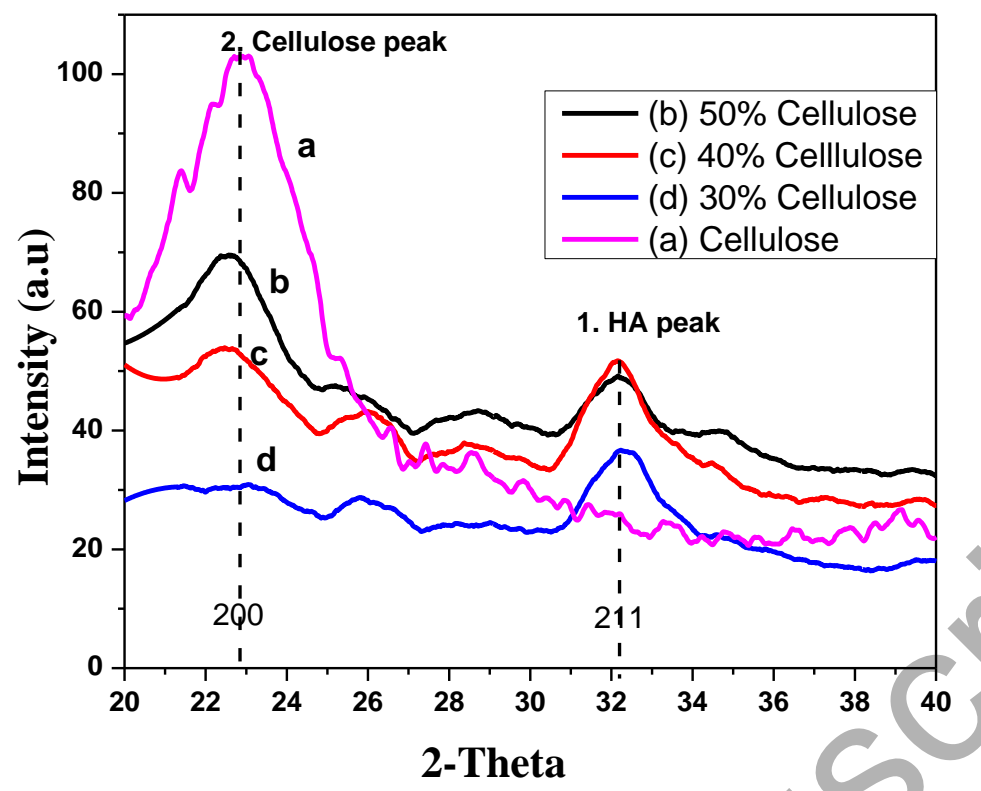

Figure 2: XRD analysis of cellulose/hydroxyapatite, the broad peaks at 2 theta values of 22.4 (crystal plane 200) and 32.2 (crystal plane 211), assigned to cellulose (JCPDS: 00-50-2241) and HA (JCPDS: 9-432), respectively 


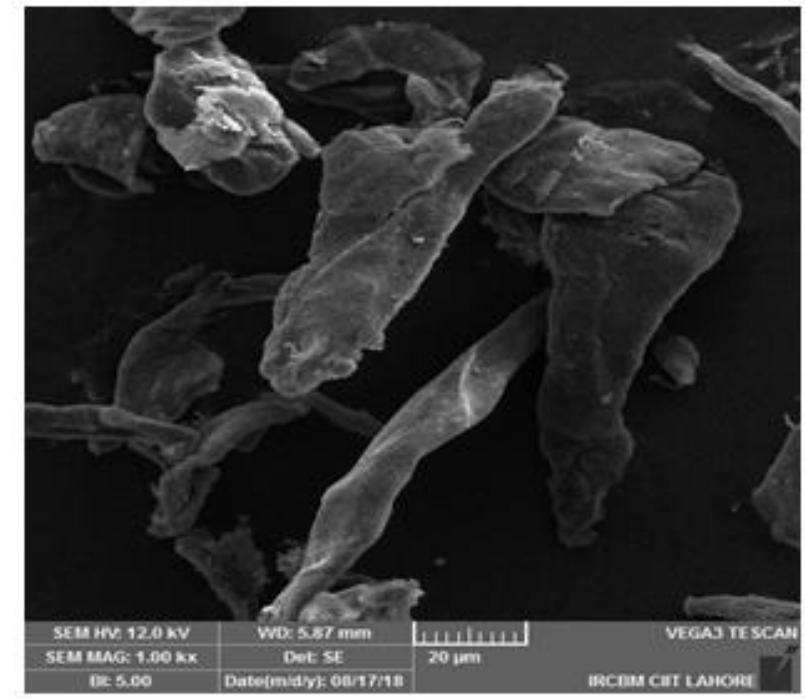

(a) Cellulose

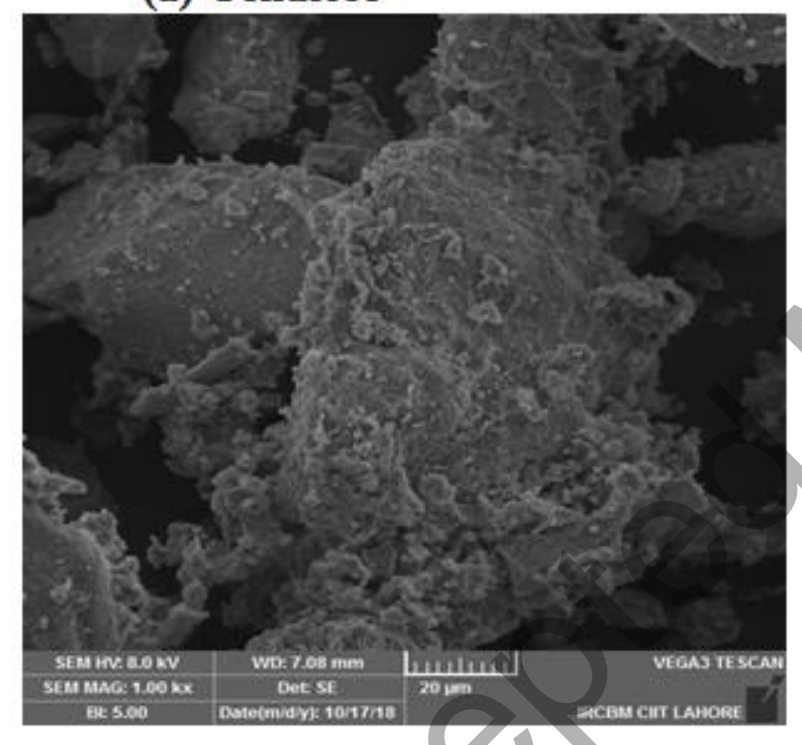

(c) $40 \%$ Cellulose of $\mathrm{HA}$

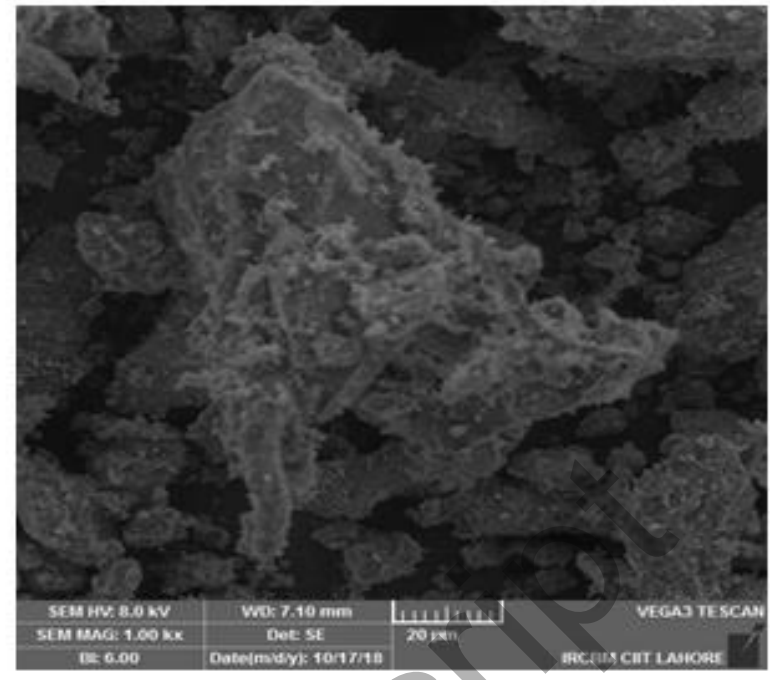

(b) $30 \%$ Cellulose of HA

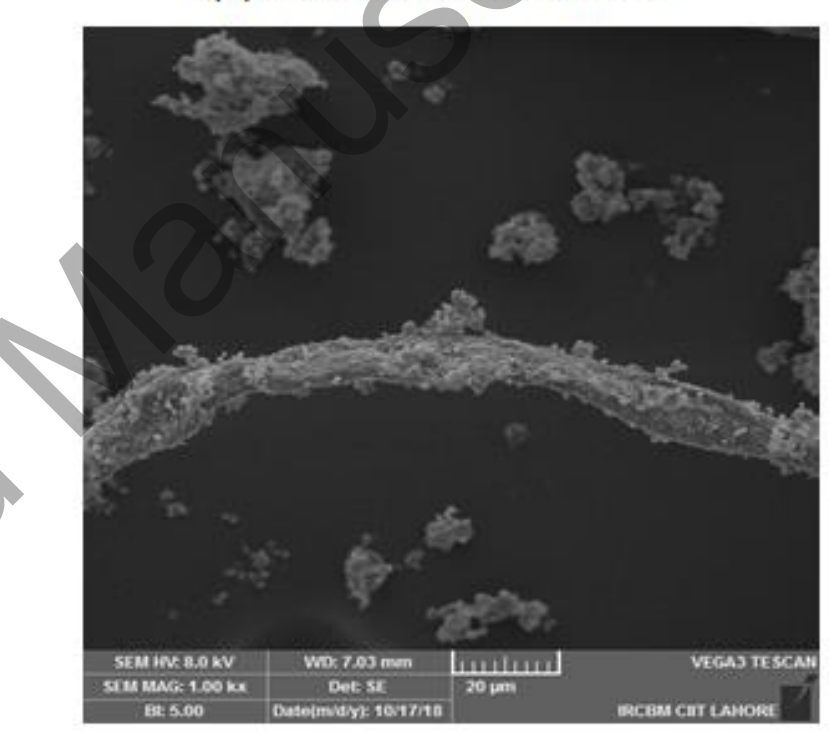

(d) $50 \%$ Cellulose of HA

Figure 3: SEM analysis of microcrystalline cellulose and cellulose/Hydroxyapatite 


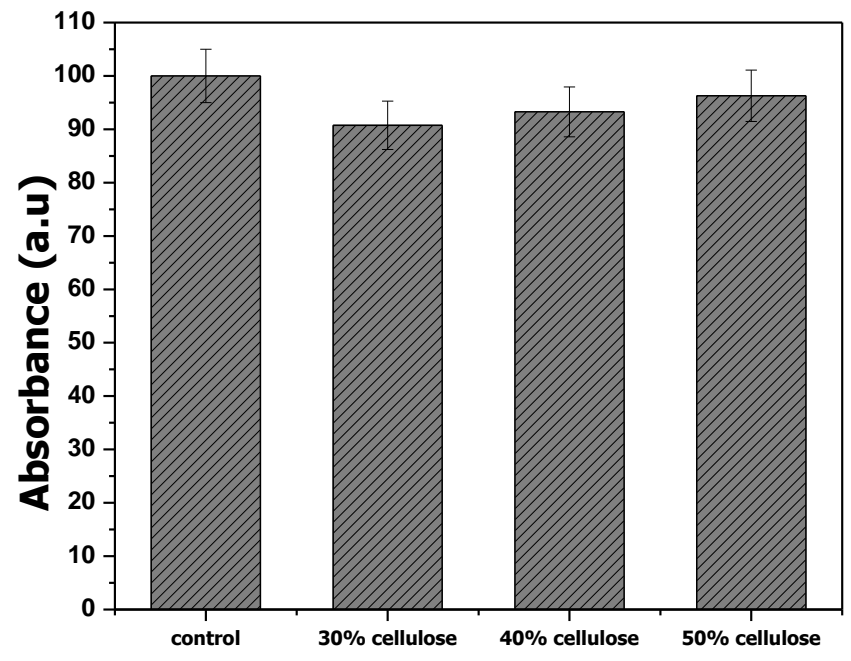

Figure 4: Cell viability assay of cellulose/hydroxyapatite 


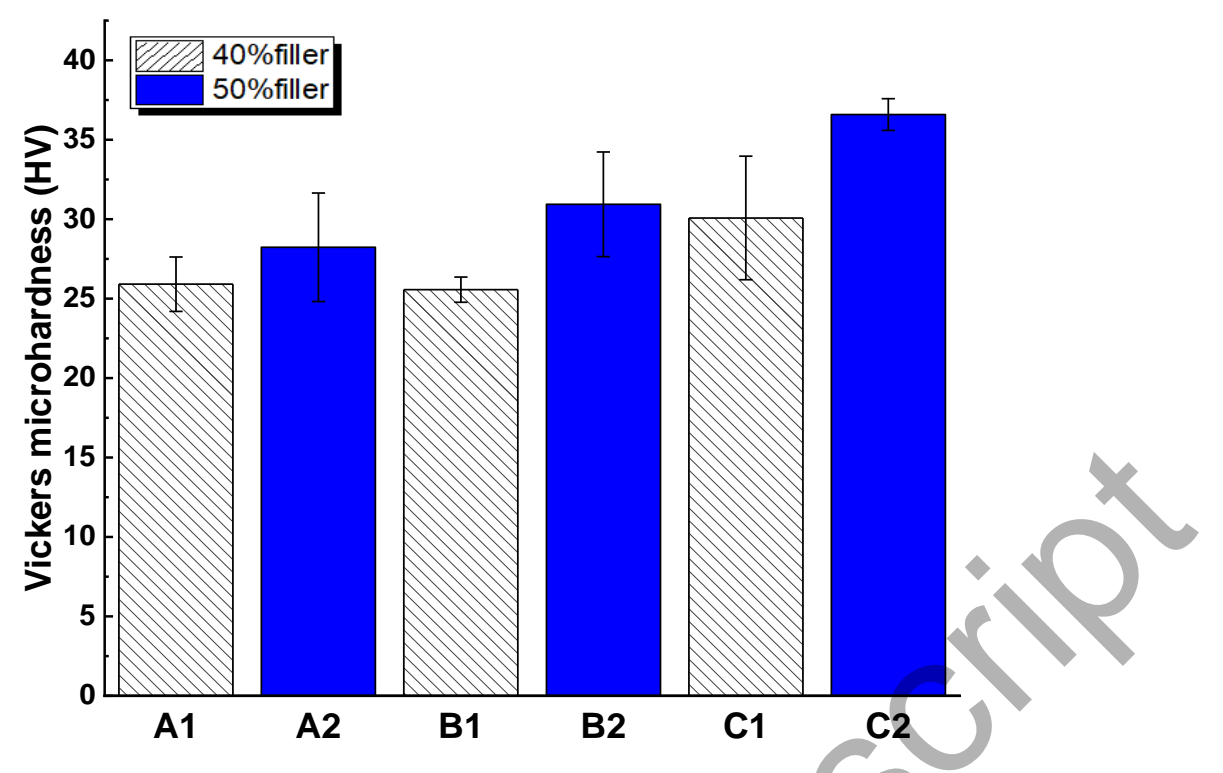

Figure 5: Vickers microhardness of dental composites 


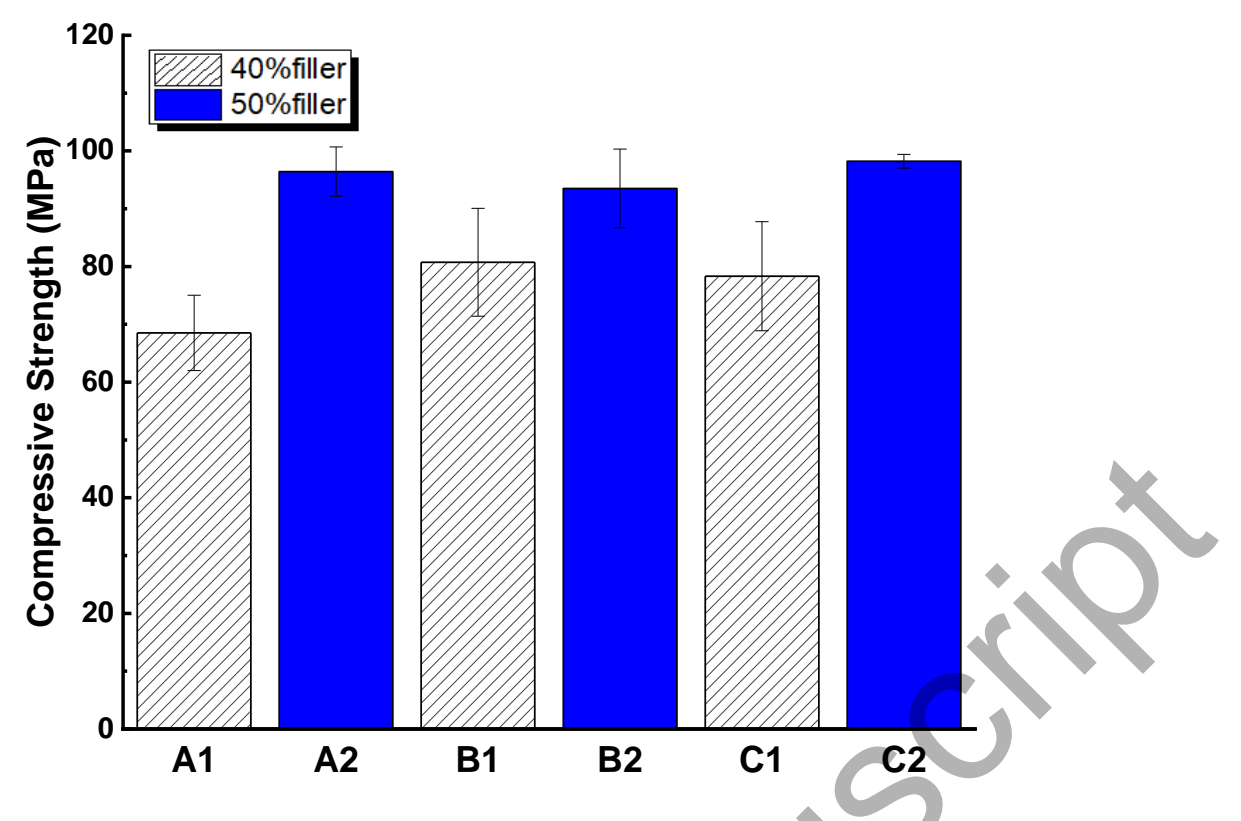

Figure 6: Compression Strength of dental composites 
(A)
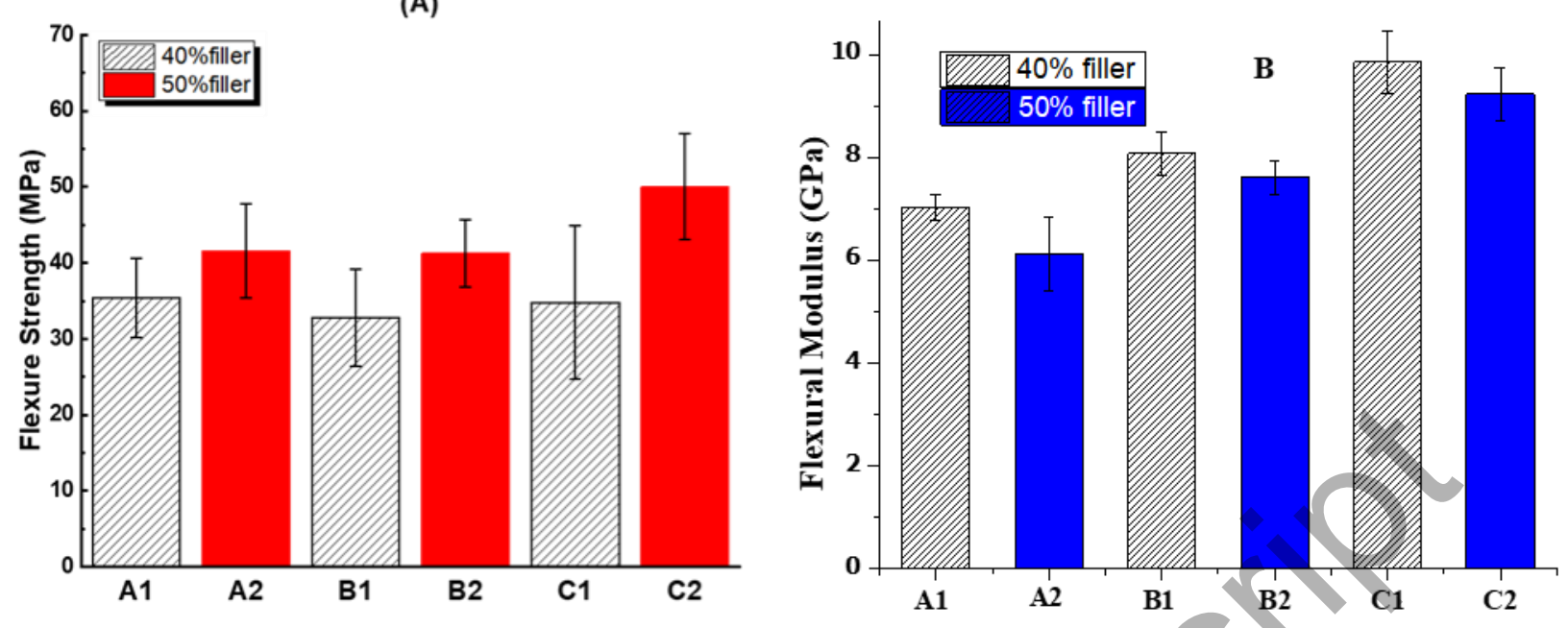

Figure 7: Flexural strength and modulus of dental composites 


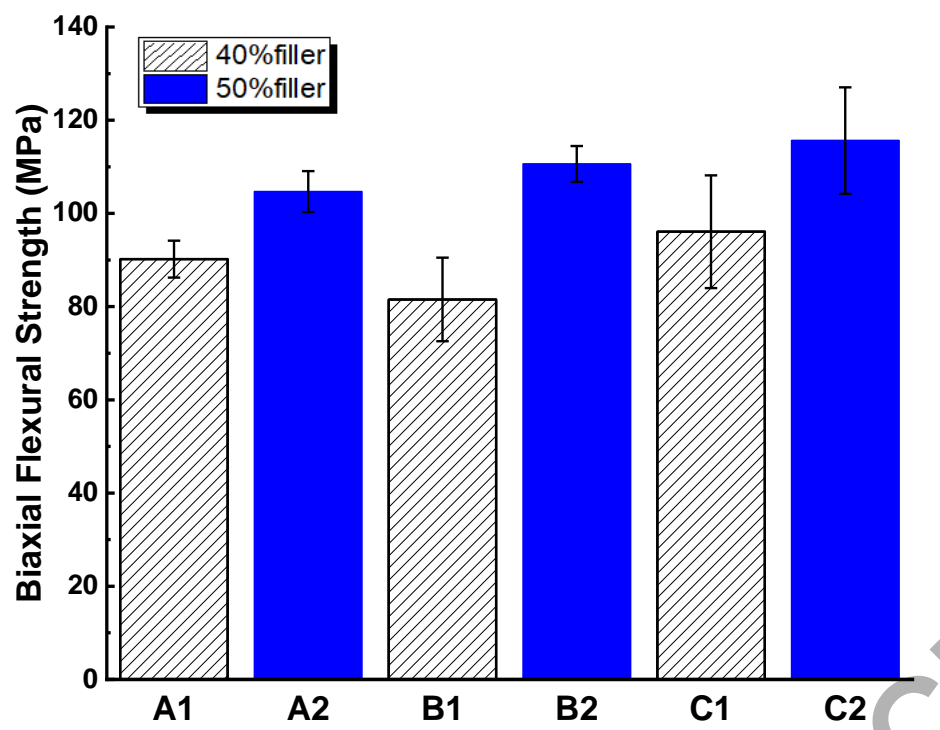

Figure 8: Biaxial flexural strength of dental composites 